\title{
Force Field Analysis on the Transformation of Archival Management
}

\author{
Xuehua Xu \\ Shandong Technology and Business University \\ Yantai, Shandong, 264005
}

\begin{abstract}
At present, the social management paradigm in China is transforming from management-oriented one into service-oriented one. Such transformation will definitely influence archival management paradigm, thus it has to adapt to external changes by adjusting its internal structure. As a management tool, the archive has always been the private goods of ruling class and archival management department is also considered as the accessory of government sector. Due to increasingly popular modern democratic idea, continuous social progress and mature market economic system, archives and archival information are not just controlled, owned and used by government. As an important information resource, it should serve for the whole society and the public and be developed and utilized in a broader way. In the new era, we need to reexamine the value and significance of archives and realize that the serviceoriented paradigm is taking shape under the background of public management. Then in the process of transformation, what kind of changes will archival management paradigm experience? How does it change? What are the reasons for these changes? How long will it last? This paper intends to introduce the theory of force field analysis and its model from physics to study the transformation of archival management paradigm to answer the above-mentioned questions and come up with corresponding solutions in order to accelerate the advent of service-oriented paradigm of archival management.
\end{abstract}

Keywords-archival management, management paradigm, force field analysis

\section{BACKGROUND AND SIGNIFICANCE OF THE RESEARCH}

\section{A. Research background}

Nowadays, China has witnessed continuous development and progress in economy, culture and politics. It is required by the times that archival management paradigm change without notice in our country. After decades' development and research, closed archival management model cannot accommodate to opened social management model any more. Archivist circle has made their own scientific judgment and prediction on existing situation and future trend of archival management in our country. And scholars have described future development patterns of archival management paradigm in China--shifting from the management-oriented paradigm into service-oriented one. What is different from old paradigm subordinating to the government is that archivist circle pays more and more attention to the existence of the public and archives attach greater importance to social needs. Entering into new century, archival management organization has experienced new

Found Project: Shangdong planning research project of social science in 2016--the phased research achievement of "Research on the Cultivation of College Students'Ability on Innovative Entrepreneurship Connecting with Supply side reform--From the Perspective of Entrepreneurial Archives" (16CZLJ15) changes. New-type archives and data management organizations such as records center, current documentation utilization center have verified such increasing social needs for archives. Archives and archival organizations are not merely restricted to serve for government but create more values for social development.

\section{B. Research significance}

As Kuhn said, the existence of archival management paradigm in our country will ultimately bring abnormal crisis of scientific revolution and old paradigm will be replaced by new one. In such dynamic transformation, each phase has different factors to affect the development of paradigm. So, if archival management paradigm begin to change, then the research and analysis on complicated internal and external factors from disciplinary community including power, resistance and pressure are extremely important for academic community to sort out the process of disciplinary formation and grasp its development trend. These factors have a direct bearing on the development of paradigm and the speed of development. And the process of paradigm revolution is different from material changes both at macro and micro levels. We usually cannot directly quantize, count, control and operate intangible subject. Under such complicated situation, it is wise to indirectly learn and master its changes with the help of other tools. The author intends to reify the factors influencing the transformation of archival management paradigm by using "force field analysis" from physics to analyze its drawbacks and benefits. With a definite objective in our mind, we should have in-depth understanding on and master the impact of each force factors in the revolution so as to draw on advantages and avoid disadvantages, ultimately promoting the transformation of existing archival management paradigm into scientific one.

By using force field analysis, this paper studies the transformation of existing archival management paradigm to solve the impact of social changes on the work of archival management. As an archivist, it is conducive to propose effective strategies and channels to balance the impact of revolution on practical work by examining the transformation of archival management paradigm, grasping "new things" in professional field and figuring out various factors influencing the transformation. With regard to archival undertaking, it is benefit to clarify the over-all environment and future direction of development of the transformation of paradigm to "pinpoint" itself and grasp new characteristics and problems in the period of transformation to guarantee the accuracy of judgment and decision. With respect to the public, it is not only about the 
different habit of using academic terms in exploring the transformation of archival management paradigm, but also to study the fundamental change of administrative idea and value orientation provided by "products" of public service hidden in the field of the whole social public management.[1]

\section{PARADIGM AND ITS TRANSFORMATION}

Kuhn once described paradigm in his book The Structure of Scientific Revolutions: "What I call paradigm usually refers to those widely-recognized scientific achievements which can provide classic questions and answers for community of practice in a period of time." From such description, we can conclude that paradigm has the following characteristics. First, only those classic and recognized by academic community can be called as paradigm. Second, paradigm can be used to guide practical work. Third, paradigm has been changing and has time limitation. From the point view of Kuhn, the theoretical basis and practical standard of what we call regular scientific disciplines are shared world view and behavioral pattern of scientific community. In a word, paradigm collectively refers to matters recognized by disciplinary community. In addition, Kuhn puts forward the transformation model of paradigm in general scientific development according to his own understanding: pre-paradigm--regular science (abnormal cases occur)--crisis-scientific revolution--formation of new paradigm... It found from the suspension points of this model that the track of the development of paradigm is cyclic progression. Cycle refers to the cyclic progression of each change which experiences these five steps of pre-paradigm, regular science, crisis, scientific revolution and new paradigm. Instead of infinite loop, the circulation of paradigm is the one which is replaced by a higher paradigm continuously.[2]

\section{ARCHIVAL MANAGEMENT PARADIGM}

Archival management paradigm, as its name implies, is a management model or pattern recognized by academic community of archives in the practice of archival management. It includes theoretical basis and practical standard recognized and highly praised by scholars of archives for a long time on which a series of researches and practical activities rely, such as archives theory, management regulation, technical standard, etc. In some sense, it is the shared world view, value and code of conduct of scholars of archives.[3] Due to the nature of paradigm, archival management paradigm has been changing and also experiences the transformation model of paradigm in general scientific development: pre-paradigm--regular science (abnormal cases occur)--crisis-scientific revolution--formation of new paradigm... Archives has always been considered as a tool used by ruling class to govern a country and archival management department has also been regarded as the accessory of ruling class to safeguard its regime. The significance of its existence aims to guarantee each function of government to work smoothly, thus the service-oriented governmental paradigm of archival management comes into being in our country. Since 1980s, the theory of information on archives has widely been recognized by scholars in China. It is believed by both theoretical circle and practice circle that archives, as an important information resources, is supposed to be developed and utilized socially in a broader manner.
Therefore, archivist circle begins to reexamine the value and significance of archives and realize that the service-oriented paradigm of archival management is taking shape under the background of public management. It can be said that the rules and laws of management paradigm in the field of public management are the same and the development track of archival management paradigm can also be summarized as the transformation from governmental paradigm into social one.[4]

\section{THE APPLICATION OF THE PRINCIPLES OF FORCE FIELD} ANALYSIS IN THE TRANSFORMATION OF PARADIGM

Although the model of Lewin aims to expound the principles of related revolution in enterprises organization, I think that such analytical method can also be applied in the field of public management or even archival management. According to Lewin's force field model, under the background of public management, archival management paradigm experiences the transformation from government-oriented into society-oriented one, in the process of which two driving movements with opposite effect exist.[5] Since archives is a branch discipline of social science, the author intends to build force field model of the transformation of paradigm in archival management and practice in our country, makes in-depth analysis on the configuration of these two driving movements in the process of transformation and proposes that the assumption on the future development of paradigm is feasible. In the meantime, Lewin divides a scientific transformation into three phases: unfreezing phase, transforming phase and freezing phase which can be used to summarize each development of science. After these three phases, stable and new science comes into being and then goes through next transformation process in a changing and continuous manner. Kuhn and Lewin have the same view on the process of scientific revolution. Then it is feasible to analyze the transformation of archival management paradigm by using force field. To reify paradigm as force body, it is influenced by power and resistance in vertical and horizontal dimension and pressure, the resultant force and direction of force of which are the ultimate direction of transformation for archival management paradigm. Knowing the causes, we can speed up the arrival of its results in advance.[6]

\section{FORCE FIELD ANALYSIS ON THE TRANSFORMATION OF ARCHIVAL MANAGEMENT PARADIGM}

Resistive restriction will propel itself forward dynamically. In the process of the transformation from government-oriented into society-oriented paradigm in archival management in our country, multiple factors such as the guidance of public value, the promotion of social needs, inevitable choice of practical work jointly constitute the driving force of the transformation of paradigm. Power and resistance are against each other and jointly impact the movement of archival management paradigm under the influence of pressure field.[7]

Archival management paradigm in our country is experiencing the initial phase of revolution. In the force field model, power, resistance and pressure all affect its direction and speed. By analyzing the force field of transformation, its development path will continue to follow such model of 
government-oriented paradigm--revolutionary process-society-oriented paradigm under the condition of dynamic equilibrium with asymmetrical relation. Aiming to the particular characteristic of force field of transformation, how archivists plan their current and future career path of archives and how to speed up the arrival of society-oriented paradigm.[8]

\section{REFLECTION ON PROMOTION OF SOCIETY-ORIENTED ARCHIVAL MANAGEMENT IN THE FUTURE}

Marx has such elaboration in materialism: everything is dynamic and changing. Old things must be replaced by new ones and the same is true of management paradigm. The consciousness and thinking of human beings cannot directly affect the transformation of paradigm, but we can use the model of transformation to analyze various factors, intervene in the objective development path on purpose, reduce resistance and increase power and accelerate the transformation of paradigm after making judgment on the future direction of development. New things must replace old ones and higher form of archival society-oriented paradigm definitely replaces old government-oriented paradigm. In such process of transformation, archivists can give their subjective initiative into full play, adhere to the principles of emphasizing the priorities, improvement step by step and guidance of government and intervene in force field of the transformation of archival management paradigm from the aspects of increased dynamic factor and reduced resistance factor, thus speeding up the arrival of archival society-oriented paradigm.

\section{CONCLUSION}

It is a rather long and hard way to transform management paradigm for a country and a society. As it were, such transformation is extremely difficult for our country and this industry in particular, which requires concerted effort of generations of archivists. Social management paradigm in China is shifting from management-oriented into serviceoriented one, which will definitely influence archival management paradigm, thus it has to adapt to external changes by adjusting its internal structure. As a management tool, the archive has always been the private goods of ruling class and archival management department is also considered as the accessory of government sector. Due to increasingly popular modern democratic idea, continuous social progress and mature market economic system, archives and archival information are not just controlled, owned and used by government. As an important information resources, it should serve for the whole society and the public and be developed and utilized in a more wider way. In the new era, we need to reexamine the value and significance of archives and realize that the service paradigm is taking shape under the background of public management. This paper introduces the principles of force field analysis and its model from physics to study the transformation of archival management paradigm. Our country enjoys rapid development with growing national strength and each sector and industry are also experiencing unprecedented changes. With regard to the field of archival management and practice, archivists should base on the whole public management or even the whole society to actively explore the future direction of development of paradigm in the archival management and practice, deal with opportunities and challenges in management and practice in a proper manner and accelerate its transformation, thus ultimately greeting its arrival.

\section{REFERENCES}

[1] Thomas Kuhn, The Structure of Scientific Revolutions[M]. Beijing, Peking University Press, 2003 p. 159 (In Chinese)

[2] Chen Zufen, Analysis of Paradigm on Whether the Revolution of Archives Takes Place or not[J]. Archives Science Study. (In Chinese)

[3] Ni Lijuan, Yin Hang, Research on Archival Management Practice Paradigm Based on Public Management[J]. Archives Science Bulletin, 201204 (35) (In Chinese)

[4] Xu Yao, On the Transformation of Archival Management Paradigm[J]. Sichuan Archives, 200604 (In Chinese)

[5] Zhu Li, Ding Huadong, From Govern ment to Society: Modern Archival Management Paradigm[J]. Archives and Construction, 200510(11) (In Chinese)

[6] Ding Huadong, Theoretical and Paradigm Analysis of Archives[M]. Shanghai: World Publishing Corporation, 2011. (In Chinese)

[7] Li Yanzhong, Force Field Analysis on the Market-Oriented Public Service in China: [J]. Future and Development, 2007(5):60 (In Chinese)

[8] Zhang Wenzhong, Force Field Analysis on Business Management[J]. Foreign Economics and Management, 198(6):19-22 (In Chinese) 